\title{
Publisher Correction: Unravelling the structure of glycosyl cations via cold-ion infrared spectroscopy
}

Eike Mucha1,2, Mateusz Marianski (1) ${ }^{1,4}$, Fei-Fei Xu ${ }^{3}$, Daniel A. Thomas (D) ${ }^{1}$, Gerard Meijer (D) Gert von Helden (D) ${ }^{1}$, Peter H. Seeberger ${ }^{2,3}$ \& Kevin Pagel ${ }^{1,2}$

Correction to: Nature Communications https://doi.org/10.1038/s41467-018-06764-3; published online 09 October 2018

The original version of this Article contained an error in Fig. 1, in which an oxygen atom was missing from the 'Acetoxonium type' structure. The correct version of Fig. 1 is:

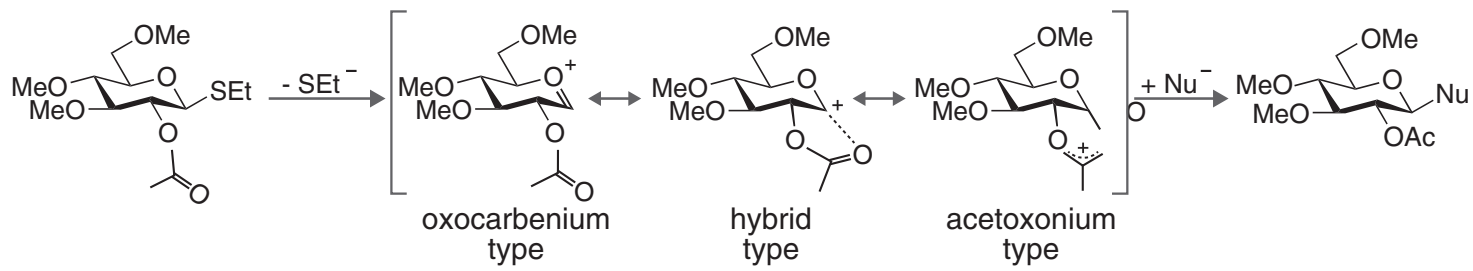

Fig. 1

which replaces the previous incorrect version shown below as Fig. 2:

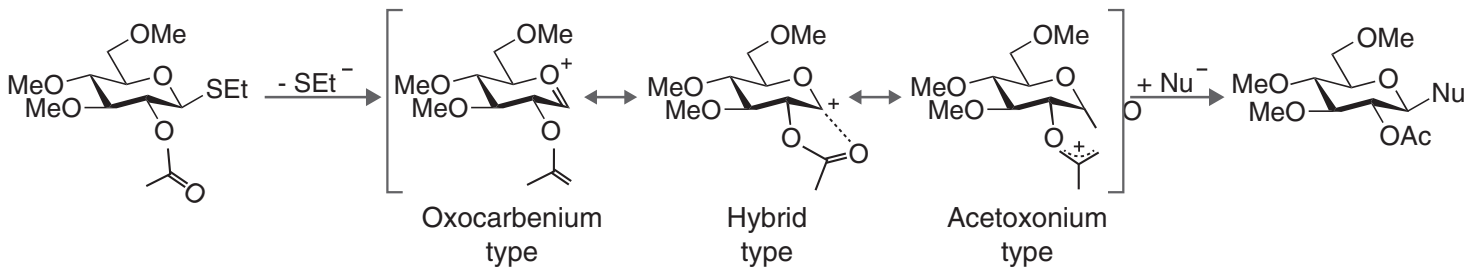

Fig. 2

This has been corrected in both the PDF and HTML versions of the Article.

Published online: 08 November 2018

\footnotetext{
${ }^{1}$ Department of Molecular Physics, Fritz Haber Institute of the Max Planck Society, Faradayweg 4-6, 14195 Berlin, Germany. ${ }^{2}$ Institute of Chemistry and Biochemistry, Freie Universität Berlin, Takustraße 3, 14195 Berlin, Germany. ${ }^{3}$ Department of Biomolecular Systems, Max Planck Institute of Colloids and Interfaces, Am Mühlenberg 1, 14476 Potsdam, Germany. ${ }^{4}$ Present address: Hunter College, The City University of New York, 695 Park Ave, New York, NY 10065, USA. These authors contributed equally: Eike Mucha, Mateusz Marianski. The original article can be found online at https://doi.org/10.1038/s41467018-06764-3. Correspondence and requests for materials should be addressed to P.H.S. (email: peter.seeberger@mpikg.mpg.de)

or to K.P. (email: kevin.pagel@fu-berlin.de)
} 


\section{COMMUNICATIONS}

(c) (i) Open Access This article is licensed under a Creative Commons Attribution 4.0 International License, which permits use, sharing, adaptation, distribution and reproduction in any medium or format, as long as you give appropriate credit to the original author(s) and the source, provide a link to the Creative Commons license, and indicate if changes were made. The images or other third party material in this article are included in the article's Creative Commons license, unless indicated otherwise in a credit line to the material. If material is not included in the article's Creative Commons license and your intended use is not permitted by statutory regulation or exceeds the permitted use, you will need to obtain permission directly from the copyright holder. To view a copy of this license, visit http://creativecommons.org/licenses/by/4.0/.

() The Author(s) 2018 